\title{
NVP-BEZ235 synergizes cisplatin sensitivity in osteosarcoma
}

\author{
Jin-Cheng Huang ${ }^{1,2, *}$, Zhi-Fei Cui ${ }^{1, *}$, Shui-Mu Chen ${ }^{1, *}{ }^{,}$Lian-Jun Yang ${ }^{1}$, Hong- \\ Kai Lian ${ }^{2}$, Bin Liu ${ }^{1}$, Zhi-Hai Su${ }^{1}$, Jin-Shi Liu ${ }^{1}$, Min Wang ${ }^{1}$, Zheng-Bo Hu${ }^{3}$, Jia-Yao \\ Ouyang ${ }^{1}$, Qing-Chu Li ${ }^{1}$ and Hai Lu' ${ }^{1}$ \\ ${ }^{1}$ Department of Orthopedics, The Third Affiliated Hospital of Southern Medical University, Academy of Orthopedics, Guangdong \\ Province, Guangzhou 510665, China \\ ${ }^{2}$ Department of Orthopedics, Zhengzhou Central Hospital, Zhengzhou University, Zhengzhou 450000, China \\ ${ }^{3}$ Department of Orthopedics, The Affiliated Shaoguan Hospital, Southern Medical University, Orthopedic Institute of \\ Shaoguan, Shaoguan 512000, China \\ * Co-first authors
}

Correspondence to: Qing-Chu Li, email: lqc16@263.net

Hai Lu, email: luhai_china@163.com

Keywords: osteosarcoma (OS); cisplatin; chemotherapy; autophagy

Abbreviations: OS: Osteosarcoma;PI3K:Phosphoinositide 3-kinase; mTOR:mammalian target of rapamycin; 3-MA: 3-Methyladenine; CQ: Chloroquine Phosphate.

Received: May 29, $2017 \quad$ Accepted: December 13, $2017 \quad$ Published: December 27, 2017

Copyright: Huang et al. This is an open-access article distributed under the terms of the Creative Commons Attribution License 3.0 (CC BY 3.0), which permits unrestricted use, distribution, and reproduction in any medium, provided the original author and source are credited.

\section{ABSTRACT}

Osteosarcoma(OS) remains a major health concern in childhood and adolescence, although cisplatin is one of the gold standard chemotherapeutic drugs in the treatment of OS, chemoresistant to cisplatin is common. Phosphoinositide 3-kinase (PI3K)-Aktmammalian target of rapamycin inhibitor ( $\mathrm{MTOR}$ ) pathway and autophagy regulates chemosensitivity incancer cells. In this study, we hypothesized that NVP-BEZ235, a dual inhibitor of PI3K/mTOR, could synergize cisplatin sensitivity in OS. In vitro, NVP-BEZ235 plus cisplatinexerted a synergistic effect on cell proliferation inhibition and apoptosis induction. Cisplatin could activate PI3K-Akt-mTOR pathway activity in early times, whereas, NVP-BEZ235 could inhibit PI3K-Akt -mTOR pathway activity all the times alone or combined with cisplatin. What's more, NVP-BEZ235 could switch function of autophagy induced by cisplatin to synergize cisplatin sensitivity. In vivo, pronounced decrease in tumor cell proliferation and increase in apoptosisin combination-treated mouse xenograft models compared with cisplatin or NVP-BEZ235 treated models. All these results suggest NVP-BEZ235 could synergize cisplatin sensitivity in OS, combination of NVP-BEZ235 with cisplatin could represent a novel therapeutic strategy for treatment of OS.

\section{INTRODUCTION}

Osteosarcoma(OS) is a commonmalignant bone tumor predominantly seen in childhood and adolescence.Despite the combination of adjuvant chemotherapy and surgical removal of the tumor has improved the 5-year-survival rates dramatically, the 5-year-survival rates haven't improved in the past 30 years $[1,2]$. To some extent, the underlying reason behind this may be chemoresistance.Although cisplatinbelongs to the gold standardMAP (methotrexate, cisplatin, doxorubicin) regimenin the treatment of OS $[2,3]$, high risk of cisplatin-associated nephrotoxcitiy, ototoxicity and gonadal dysfunction limit its individual doses [4], what's more, lots of patients are resistant to cisplatin. Thus, development of novel treatment strategies for enhancing cisplatin sensitivity in OS is imperative.

Phosphoinositide 3-kinase (PI3K)-Akt-mammalian target of rapamycin inhibitor (mTOR) pathway takes part in lots of disparate cellular functions(cell growth, proliferation, autophagy, apoptosis, chemo-resistance) and has been considered as a promising drug target for cancer therapy $[5,6]$. For the past few years, PI3K-Akt- 
mTOR pathway was shown to participate in osteosarcoma development and metastasis [7-9], however, its role on OS chemoresitanceis unclear.

Autophagy, an evolutionarily conserved process, mediates lysosomal degradation of cytoplasmic and cellular organelles, plays an important role in maintaining the homeostasis $[10,11]$. It is generally thought that autophagy has four functions in cells confronted with different conditions: cytoprotective, cytotoxic, cytostatic and nonprotective [12]. Recently, researches showed that autophagy induced by MAP in OS could promote chemoresitance $[13,14]$ andautophagy targeting methods could be used to enhance chemosensitivity in cancer cells [15-18].

NVP-BEZ235, a dual PI3K/mTOR inhibitor, couldinhibit the activity of PI3K-Akt-mTOR pathwayand the proliferation of OS cancer cells effectively [19, 20]. Moreover, in some cisplatin-resistant tumor cell lines, NVP-BEZ235 could enhance their cisplatin sensitivity [21-23]. However, whether NVP-BEZ235 could synergize cisplatin sensitivity or not in OS is still unknown.

In this study, we demonstrated that NVP-BEZ235 could synergize cisplatin sensitivity in OS both in vitro and in vivo. Our results suggest that there is value in utilizing NVP-BEZ235 to sensitize OS to cisplatin.

\section{RESULTS}

\section{NVP-BEZ235 synergistically enhances the anti- proliferative effect of cisplatin on OS cells}

First, effect of NVP-BEZ235 or/and cisplatin on the proliferation of OS U2OS, Saos-2 and MG-63 cells was determined by CCK-8 assay. As shown in Figure 1A-1E, NVP-BEZ235 or cisplatinalone could inhibit the proliferations of U2OS, Saos- 2 and MG-63 cells in dose- and time-dependent manners. The 50\% inhibitory concentration (IC50) value of cisplatinand NVP-BEZ235 were shown in Table 1. Second, to test the synergistic effect between cisplatin and NVP-BEZ235, U2OS, Saos2 and MG-63 cells were exposed to increasing doses of NVP-BEZ235 or cisplatin alone or in a 20000:1 fixed ratio combination and the anti-proliferative effectwas assessed by CCK- 8 assay (Figure 1F). Third, drug synergy was measured by fraction Combination indexplot and isobologram (Figure 1G-1I).

As shown in Figure 1G-1I, both fraction Combination indexplot and isobologram showed that combination of NVP-BEZ235 with cisplatin exerteda synergistic antiproliferative effecton OS U2OS, Saos-2 and MG-63 cells.

\section{Different regulation of PI3K-Akt-mTOR pathway activity in U2OS and Saos-2 cells by cisplatin and NVP-BEZ235}

As PI3K-Akt-mTOR pathway has dual effect on chemosensitivity in cancer cells [24-26], activity of PI3K-
Akt-mTOR pathway in response to cisplatin or/and NVPBEZ235 in U2OS and Saos-2 cellscells were analyzed. As shown in Figure 2, transient increase in phosphorylated-S6 and phosphorylated-Akt (Ser473, Thr308) were seen at 1-12 hours after treatment with cisplatin, while, all phosphorylation levels were decreased at 24 hours (Figure 2A). In contrast, phosphorylated-S6 and phosphorylatedAkt (Ser473, Thr308) levels decreased at all times (1-24 hours) after treatment with NVP-BEZ235 in U2OS and Saos-2 cells (Figure 2B). We further explored cisplatininduced transient increase in PI3K-Akt-mTOR pathway activity and found a concentration dependent increase in PI3K-Akt-mTOR pathway activity at 12 hours in U2OS and Saos-2 cells (Figure 2C). While, a concentration dependent decrease in PI3K-Akt-mTOR pathway activity was found at 12 hours in U2OS and Saos-2 cells treated with NVP-BEZ235 (Figure 2D). As expected, NVPBEZ235 plus cisplatin treatment decreased the PI3K-AktmTOR pathway activity at all times (1-24 hours) in U2OS and Saos-2 cells (Figure 2E).

Collectively, these results demonstrate that NVPBEZ235 alone or combined with cisplatin could inhibit PI3K-Akt-mTOR pathway activity effectively, whereas, cisplatin could increase activity of PI3K-Akt-mTOR pathway in early times.

\section{NVP-BEZ235 synergistically induces apoptosis in U2OS and Saos-2 cells treated with cisplatin}

To better understand the mechanism underlying the combined anti-proliferative activity observed in the CCK8 assays, cell cycle progression were investigated in U2OS and Saos-2 cellsafter treatment with NVP-BEZ235 or/and cisplatin for 24 hours. As shown in Figure 3A and 3B, both NVP-BEZ235 and cisplatin single-agent treatment caused significant changes in cell cycle distribution, what's more, concomitant treatment resulted in a marked increase of cells in the sub-G1 phase compared with the untreated control, NVP-BEZ235, or cisplatinsingle-treated cells.

Next, the effect of NVP-BEZ235 or/and cisplatin on apoptosis was determined. U2OS and Saos-2 cells were exposed to NVP-BEZ235 or/and cisplatin for 24 hours, then stained with Annexin V-FITC and PI and analyzed by flow cytometry. As shown in Figure 3A, combined treatment with NVP-BEZ235 and cisplatin in U2OS and Saos-2 cells for 24 hours induced more apoptosis rates than treated with NVP-BEZ235 or cisplatin alone $(P<0.05)$. Also, fluorescence microscopy examination revealed similar results (Figure 3B).In addition, cleaved PARP and cleaved caspase- 3 were significantly elevated compared to the cisplatin or NVPBEZ235 groups (Figure 3C).

All these suggest that NVP-BEZ235 synergistically induces apoptosis in U2OS and Saos-2 cells treated with cisplatin. 
Table 1: The inhibitory potentials of cisplatin and NVP-BEZ235 on the viability of U2OS, Saos-2 and MG-63 cells

\begin{tabular}{lcc}
\hline \multirow{2}{*}{ cells } & \multicolumn{2}{c}{ Compound/IC50 } \\
\cline { 2 - 3 } & Cisplatin (uM) & NVP-BEZ235 (nM) \\
\hline U2OS & & $198.433 \pm 0.981$ \\
Saos-2 & $10.793 \pm 0.097$ & $197.800 \pm 1.778$ \\
MG-63 & $15.643 \pm 0.193$ & $88.03 \pm 0.531$ \\
\hline
\end{tabular}

The synergistic effects of combined NVP-

BEZ235 and cisplatin weren't due to enhanced activation of the $\mathbf{p 3}$ or TAp73 pathway

Tumor suppressor p53, a transcription factor, can be activated by DNA damage to regulate a list of target genes controlling cell cycle arrest, apoptosis and autophagy [27]. TAp73, one member of the p53 family, acts activities familiar with those of p53 [28]. Previous studies have shown that inhibition of PI3K-Akt-mTOR pathway activity could increase cellular levels of p53 [29, 30] and enhance DNA damage-induced cell death in tumor cells through a p53-dependent manner [24, 31, 32]. Also, inhibition of mTOR by rapamycin can up-regulate TAp73 expression [33] and synergize cisplatin sensitivity in basal-like breast cancer cells through a TAp73-dependent manner [34]. Our previous studies also showed that TAp73 could be reactivated in p53-mutant or p53-null cancer cells to exert activities familiar with those of p53 to suppress tumor [35-37].

So, we decided to determine whether the synergistic effects of combined NVP-BEZ235 and cisplatin could
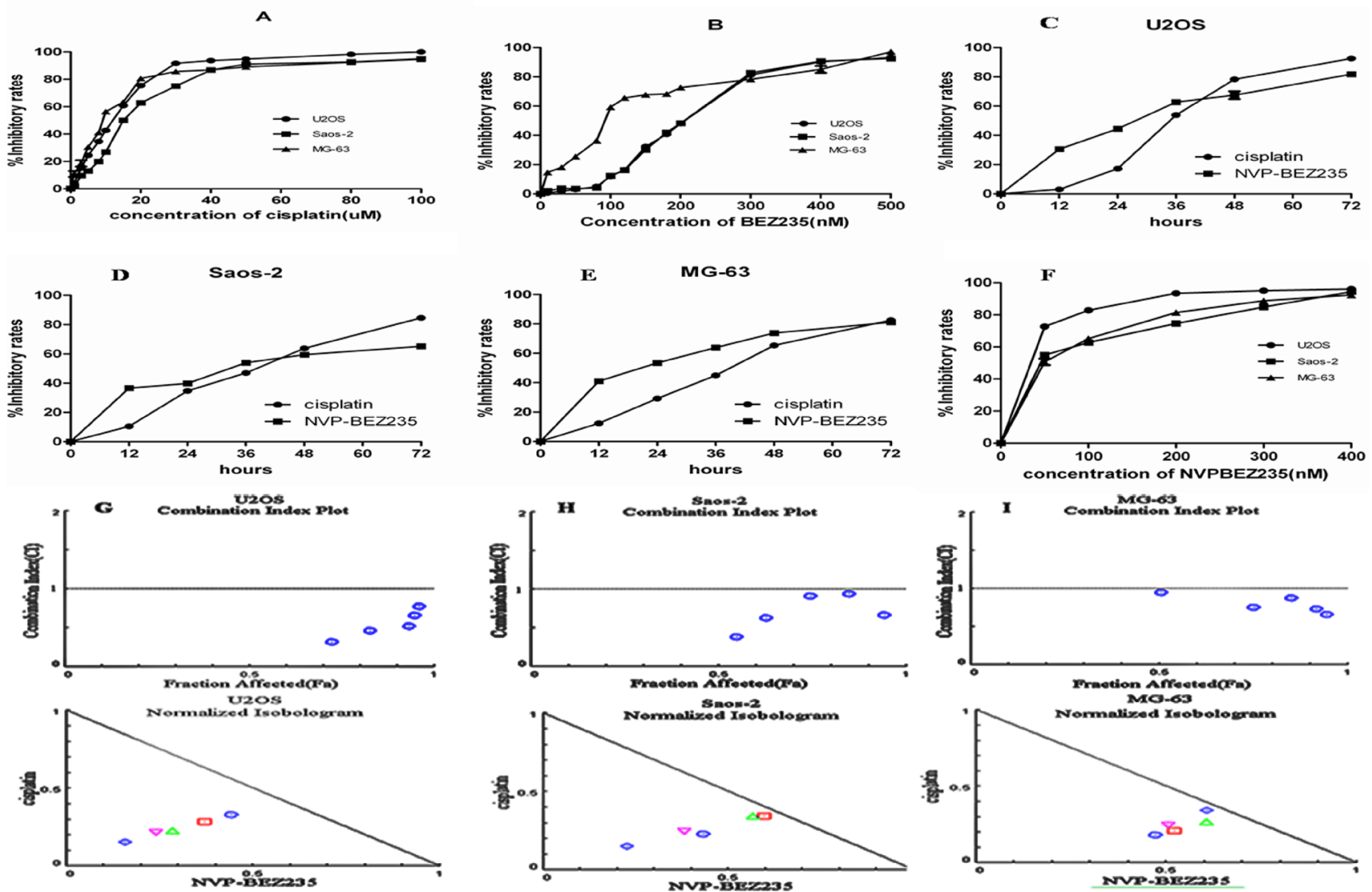

Figure 1: Effect of cisplatin or/and NVP-BEZ235 on OS U2OS, Saos-2 and MG-63 cells proliferation. Cell viability was detected by CCK-8 assay. The results were expressed as inhibitory rates of cells. (A-E) Inhibitory rates in U2OS, Saos-2 and MG-63 cells after treatment with different doses of cisplatin or/and NVP-BEZ235. (F) Inhibitory rates in U2OS, Saos-2 and MG-63 cells after treatment with a 20000:1 fixed ratio combination of NVP-BEZ235 and cisplatin. (G-I) Combination Index plot and Isobologram for combination of NVP-BEZ235 and cisplatin in U2OS, Saos-2 and MG-63 cells. The CI plot for the combinations of drugs where synergy (identified by a Combination Index $<1$ ) over a range of drug concentrations. Combination index $(\mathrm{CI})$ value was calculated using CompuSyn software. The line represents an additive affect, where $\mathrm{CI}=1$. Each data point represents the mean $\pm \mathrm{SD}$ of triplicate experiments. 
be explained by enhanced activation of p53 or TAp73 pathway in U2OS and Saos-2 cells. Surprisingly, expression of p53 and TAp73 were down-regulated in combined NVP-BEZ235 and cisplatin treatment groups than cisplatin treatment groups (Figure 4A). What's more, levels of downstream transcriptional targets of p53 and TAp73 including NOXA, p21 and PUMA were also decreased at both protein and mRNA level (Figure 4B).

So, the synergistic effects of the combined NVPBEZ235 and cisplatin weren't due to enhanced activation of the p53 or TAp73 pathway.

NVP-BEZ235 sensitizes U2OS and Saos-2 cells to cisplatin through switching function of autophagy induced by cisplatin

Autophagy, an evolutionarily conserved process, mediates lysosomal degradation of cytoplasmic and cellular organelles, plays an important role in maintaining the homeostasis $[10,11]$. It is generally thought that autophagy has tumor promotion or tumor suppression roles in different contexts $[11,12,38]$. Previous studies have demonstrated that autophagy induced by cisplatin promotes chemoresitance in OS [39, 40], and NVP-
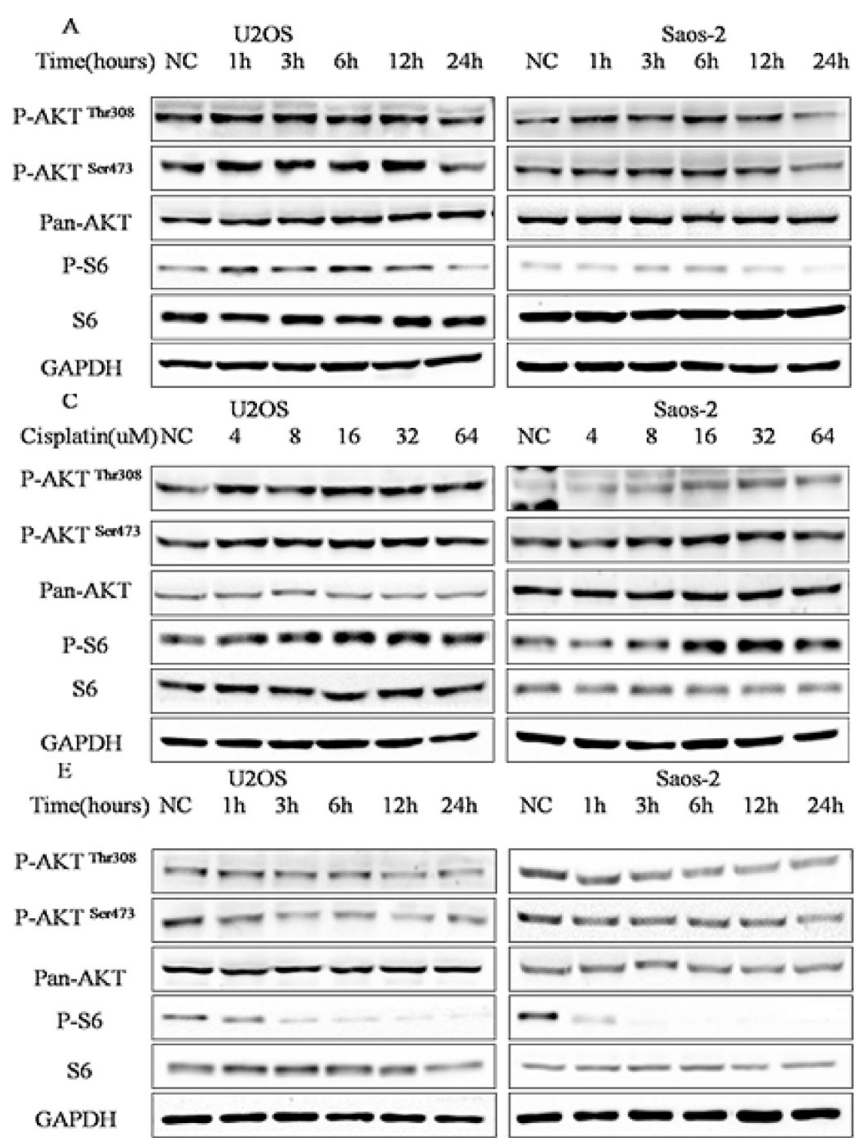

BEZ235 could enhance cisplatin sensitivity in some cisplatin-resistant cancer cells through autophagyinducing [21-23].

In order to explore whether autophagy takes part in the synergistic effects of combined NVP-BEZ235 and cisplatin, functions of autophagy induced by cisplatin or/ and NVP-BEZ235 in U2OS and Saos-2 cells were tested. As expected, cisplatin or/and NVP-BEZ235 treatment could induce autophagy in U2OS and Saos-2 cells, while 3-Methyladenine (3-MA) and Chloroquine Phosphate (CQ) could inhibit autophagy induced by cisplatin or/and NVP-BEZ235 effectively (Figure 5A-5E).

Next, functions of autophagy induced by cisplatin or/and NVP-BEZ235 in U2OS and Saos-2 cellscells were analyzed by flow cytometry after exposed to 3-MA, cisplatin, NVP-BEZ235, singly or in combination. As shown in Figure 6A, 6B, percentage of apoptotic cells in combined cisplatin and 3-MA groups were higer than cisplatin groups in both U2OS and Saos-2 cells. In U2OS cells, apoptosis rates in combined 3-MA, cisplatin and NVP-BEZ235 groups were lower than combined cisplatin and NVP-BEZ235 groups. However, in Saos-2 cells, differences of apoptosis rates among combined cisplatin
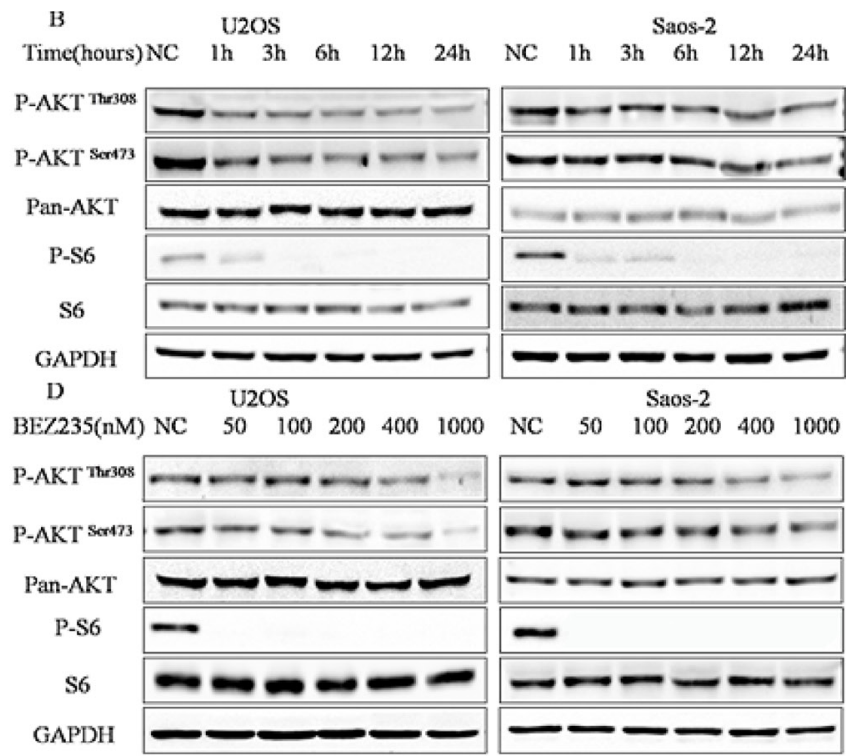

Figure 2: Different regulation of PI3K-Akt-mTOR pathway activity by cisplatin and NVP-BEZ235 in U2OS and Saos-2 cells. (A) Kinetic effect of $4 \mathrm{uM}$ or $6 \mathrm{uM}$ cisplatin in U2OS and Saos-2 cells. (B) Kinetic effect of $200 \mathrm{nM}$ NVP-BEZ235 on U2OS and Saos-2 cells. (C) Dose-ranging experiment 6 to $64 \mathrm{uM}$ cisplatin in U2OS and Saos-2 cells treated for $12 \mathrm{~h}$. (D) Dose-ranging experiment from 50 to $1000 \mathrm{nM}$ NVP-BEZ235 in U2OS and Saos-2 cells for $12 \mathrm{~h}$. (E) Kinetic effect of NVP-BEZ235 plus cisplatin treatment in U2OS and Saos-2 cells. GAPDH were used as loading controls. 


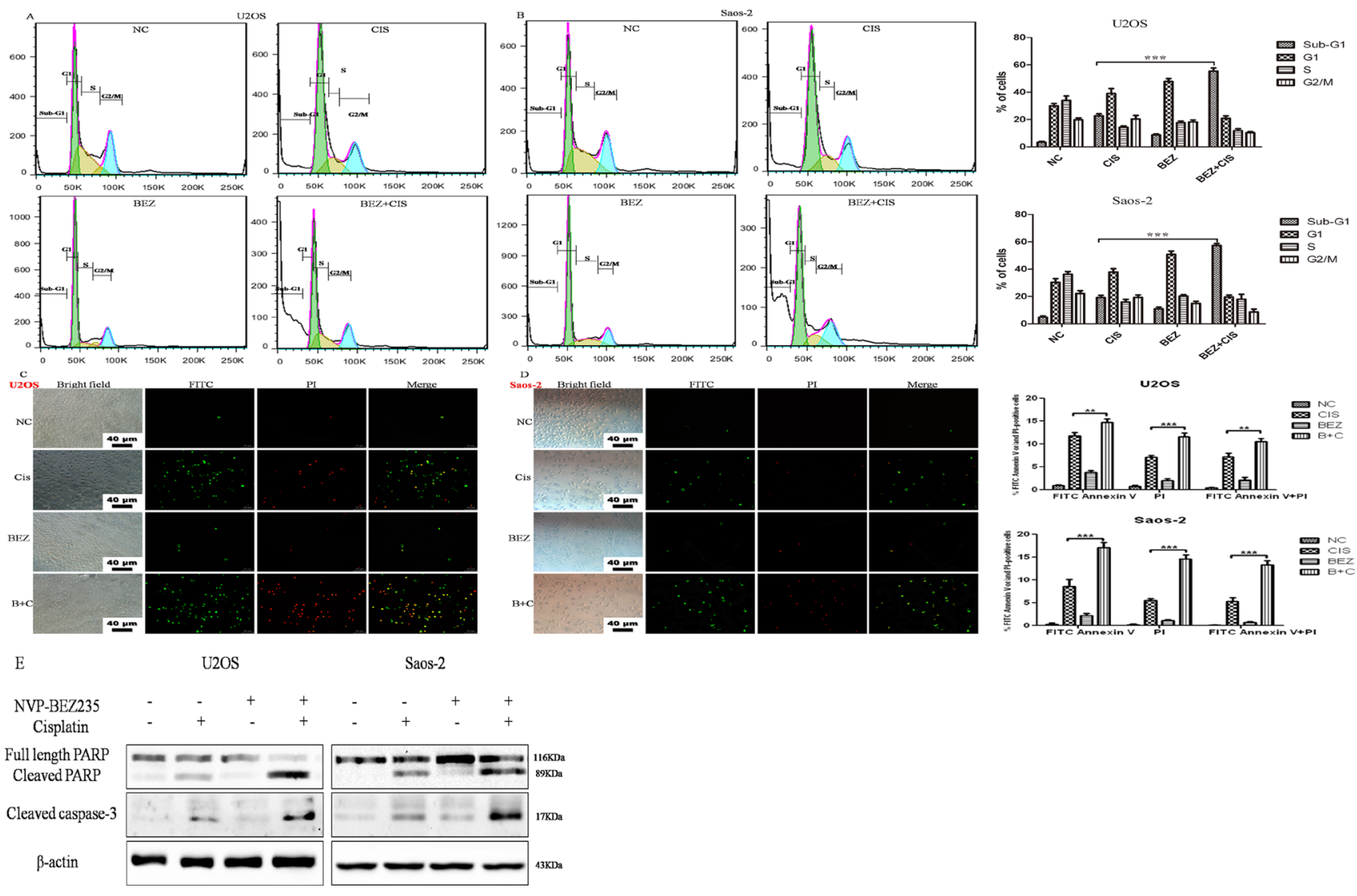

Figure 3: Effect of cisplatin or/and NVP-BEZ235 on U2OS and Saos-2 cells cell cycle progression and apoptosis. (A, B) Summary of cell cycle progression after the treatment with cisplatin or/and NVP-BEZ235 in U2OS and Saos-2 cells for 24 hours. Data is shown as the \% of cells in Sub-G1, G1, S and G2-M. (C, D) Representative results of Annexin V-PI dual staining with flow cytometry or fluorescence microscopy in U2OS and Saos-2 cells at 24 hours after treatment with cisplatin or/and NVP-BEZ235. (E) Cleaved PARP and cleaved caspase-3 were detected by Western blot in U2OS and Saos-2 cells at 24 hours after treatment with cisplatin or/and NVP-BEZ235. $\beta$-actin was used as a loading control. Each data represents the mean \pm SD of triplicate experiments. Notes: Green: stained with Annexin V-FITC; red: stained with PI; Merge: stained with both Annexin V-FITC and PI. Apoptotic cells were highlighted by FITC, PI, and their merged images. ${ }^{* *} P<0.01$ and ${ }^{* * *} P<0.001$. Scale bar $=40 \mu \mathrm{m}$. Cis is short for cisplatin, BEZ is short for NVP-BEZ235, $\mathrm{B}+\mathrm{C}$ is short for combined NVP-BEZ235 and cisplatin.
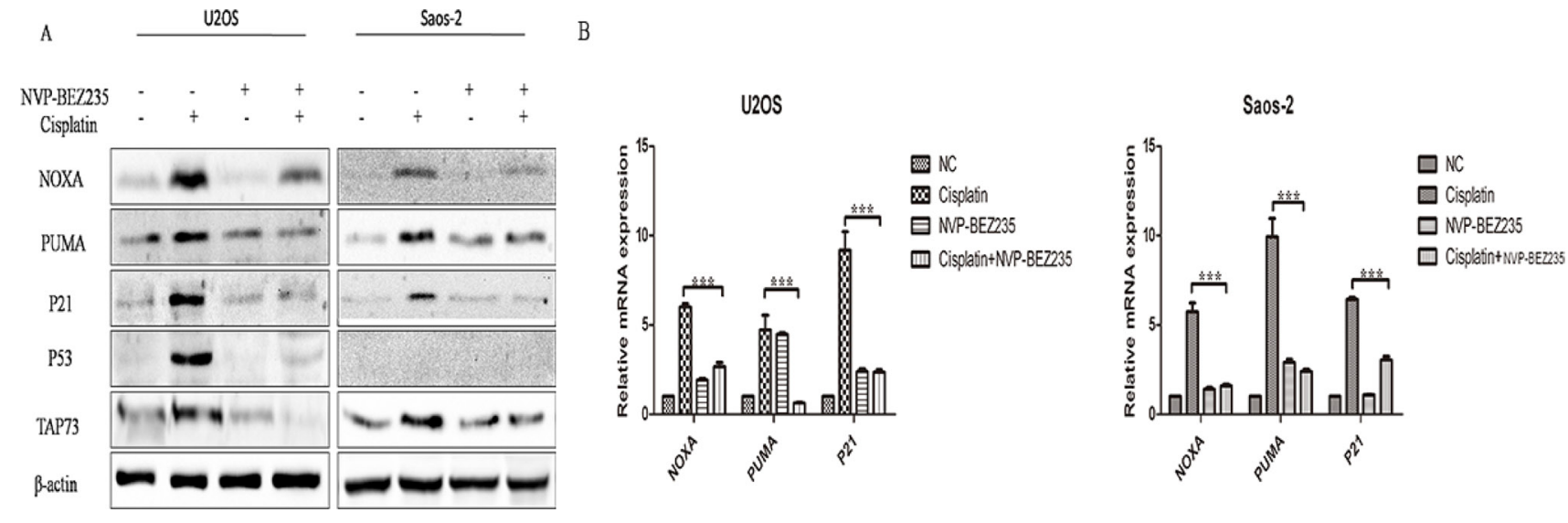

Figure 4: NVP-BEZ235 inhibits p53- and TAp73-dependent transactivation in U2OS and Saos-2 cells. U2OS and Saos-2 cells were treated with cisplatin or/and NVP-BEZ235 for 24 hours. (A) Western blot was performed to detect p53, TAp73, NOXA, PUMA and P21 expression. $\beta$-actin was used as a loading control. (B) qPCR was performed to detect NOXA, PUMA and P21 at the mRNA levels. $\beta$-actin was used as a loading control. Each data represents the mean \pm SD of triplicate experiments. 


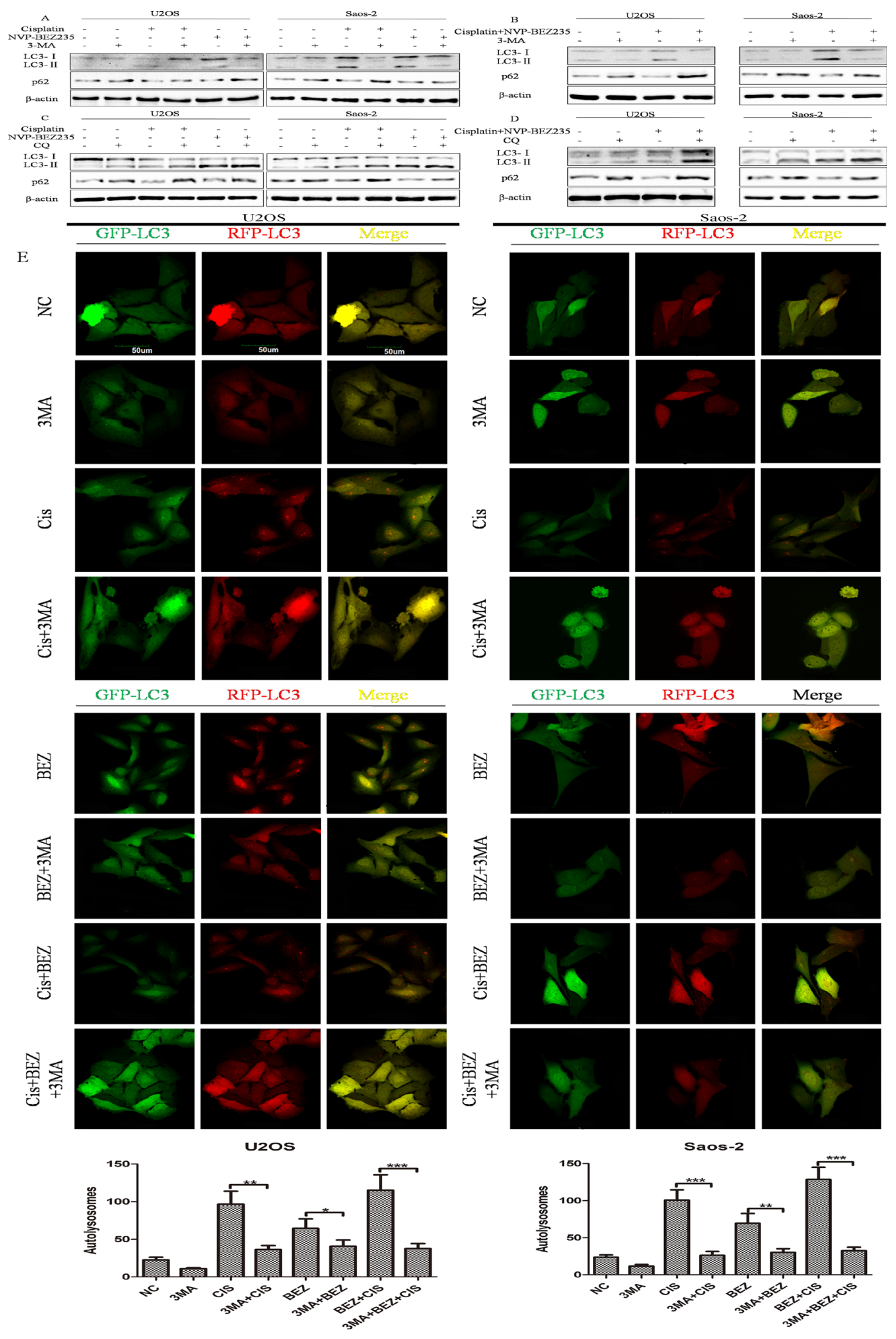

Figure 5: Cisplatin or/and NVP-BEZ235 treatment induce autophagy in U2OS and Saos-2 cells. (A-D) LC3 and p62 expressions were detected by Western blot in U2OS and Saos-2 cells after treatment with cisplatin or/and NVP-BEZ235 with or without 3-MA or CQ. $\beta$-actin was used as the loading control. (E) Autophagy flux was induced by cisplatin or/and NVP-BEZ235 and inhibited by 3-MA. U2OS and Saos-2 cells were infected with GFP-RFP-LC3 adenovirus for $36 \mathrm{~h}$ and then treated with $24 \mu \mathrm{M}$ cisplatin or/and $200 \mathrm{nM}$ NVP-BEZ235 for another $24 \mathrm{~h}$ or pre-treated with $3 \mathrm{mM}$ 3-MA for $3 \mathrm{~h}$. The GFP-RFP-LC3 fluorescence was observed by a confocal microscope. Number of autolysosomes(red vesicles minus green vesicles) were calculated in per cell $(n=5)$. Data are shown as mean $\pm \mathrm{SD}$. ${ }^{*} P<0.05,{ }^{* *} P<0.01,{ }^{* * *} P<0.001$. Scale bar $=50$ um. Cis is short for cisplatin, BEZ is short for NVP-BEZ235. 
and NVP-BEZ235 groups and combined 3-MA, cisplatin and NVP-BEZ235 groups weren't significant. Similar results were obtained through detecting expressions of cleaved PARP by Western blot (Figure 6C, 6D).

In order to exclude the possible off-target effects by 3-MA, siRNA method wasapplied to selectively knockdown autophagy protein ATG5. As shown in Figure 6E, ATG5 siRNA-1 and siRNA-2 could decrease expression of ATG5 effectivelyin both U2OS and Saos-2 cells. As expected, combined cisplatin and NVP-BEZ235 treatment induced lower apoptosis rates with ATG5 siRNA-1 silence in U2OS cells. However, differences of apoptosis rates in Saos-2 cells with or without ATG5 siRNA-1 silence treated with combined cisplatin and NVP-BEZ235 weren't significant (Figure 6F-6I). Similar results were obtained with ATG5 siRNA-2 silence.

Together, all these results show that NVP-BEZ235 sensitizes U2OS and Saos-2 cells to cisplatin through switching function of autophagy induced by cisplatin

\section{NVP-BEZ235 sensitizes OS cancer cells to cisplatin in vivo}

To detect the in vivo efficacy of combined treatment of NVP-BEZ235 plus cisplatin,U2OS xenograft mice models were established and divided into 4 groups: (1) mice treated with vehicle only, (2) mice treated with cisplatin only, (3) mice treated with NVP-BEZ235 only, (4) mice treated with combined cisplatin and NVP-BEZ235.

Tumors were allowed to develop for 35 days after injection, and therapy was started on day 7 after tumor implantation. The volume of the tumors was measured weekly until the mice were sacrificed. As shown in Figure 7A, from day 15, there were significant differences in tumor volume between combined NVP-BEZ235 and cisplatin groups and cisplatinsingle treatment groups. On day 28 , all mice were sacrificed and tumor volumes were measured. Consistent with above results, tumor volume in combined NVP-BEZ235 and cisplatin groups were lesser than mice treated with vehicle, cisplatin or NVP-BEZ235 alone (Figure 7B-7C). This indicates that NVP-BEZ235 could synergistically enhance growth inhibition effect of cisplatin in vivo.

Then, a pronounced decrease in tumor cell proliferation (Ki67) (Figure 8A, 8C) and increase in apoptosis (TUNEL-positive tumor cells) were also noted in combination-treated xenografts based on immunostaining (Figure $8 \mathrm{~B}$ ). Taken together, these data recapitulate the observations made in vitro and demonstrate that NVPBEZ235 displays synergistic activity with cisplatin in vivo xenograft models.

\section{DISCUSSION}

Although the underlying mechanisms of chemoresistancein OS have always been the focus of researchers all over the world [2, 41], identification of novel strategies to circumvent chemoresitance are still desperately required.For the past few years, PI3K-AktmTOR pathway has been demonstrated to participate in OS development and metastasis [7-9], however, its role on OS chemoresitanceis unclear.In this study, we demonstrated that NVP-BEZ235, a dual PI3K/mTOR inhibitor, could synergize cisplatin sensitivity in OS through switching function of autophagy induced by cisplatin. To our knowledge, our work is the first study trying to enhance cisplatin sensitivity in OS through switching function of autophagy by inhibition of PI3KAkt-mTOR pathway activity.

In this study, we first detected the proliferation of OS U2OS, Saos-2 and MG-63 cellsafter treatment with cisplatin or/and NVP-BEZ235. Results showed that NVP-BEZ235 could synergistically enhance the antiproliferative effect of cisplatin on OS cells. Then, cell cycle progression and apoptosis rates were analyzed. As shown in Figure 3, NVP-BEZ235 could synergistically induce apoptosis in U2OS and Saos-2 cells treated with cisplatin.All these indicate there may be possible in utilizing NVP-BEZ235 to sensitize OS to cisplatin.

As PI3K-Akt-mTOR pathway is always activated in human cancers, it is believed to be the target for inactivation in order to achieve better chemotherapy [42]. Consistent with otherstudies [21-23, 43, 44], in this study, cisplatin couldtransientlyincrease the activity of PI3KAkt-mTOR pathwaywhereasNVP-BEZ235 alone or combined with cisplatin could inhibit PI3K-Akt-mTOR pathway activity effectively.So, it seems NVP-BEZ235 may enhance cisplatin sensitivity in OS through PI3KAkt-mTOR pathway inactivation.

Tumor suppressor p53, the guardian of the genome, plays important roles in regulating chemosensitivity in cancer cells [27]. TAp73, one member of the p53 family, acts activities familiar with those of p53 [28, 45]. It's reported that inhibition of PI3K-Akt-mTOR signaling could increase cellular levels of p53, and augment p53 transcriptional activity [24, 29-32]. Similarly, mTOR inhibition also increases TAp73 expression [33] and synergizes cisplatin sensitivity in basal-like breast cancer cellsthrough a TAp73-dependent manner [34]. However, in contrast to above findings, $\mathrm{J}$ Bar et al. reported that exposure to LY294002(PI3K inhibitor), could abort the activation of $\mathrm{p} 53$ by drugs used in cancer chemotherapy [46]. Kojima, K et al. demonstrated that PI-103 (dual $\mathrm{PI} 3 \mathrm{~K} / \mathrm{mTOR}$ inhibitor), could inhibit expression of $\mathrm{p} 53$ and p53-related pro-apoptotic proteins (p21,puma,noxa) [47]. R Suvasini et al. found that LY294002 could inhibit p53 activation on DNA damage [48]. So, we first detect whether the synergistic effects of combined NVPBEZ235 and cisplatin could be explained by enhanced activation of p53 or TAp73 pathway in U2OS and Saos-2 cells. However, to our surprise,combined NVP-BEZ235 and cisplatin treatment decreased cisplatin-induced p53 

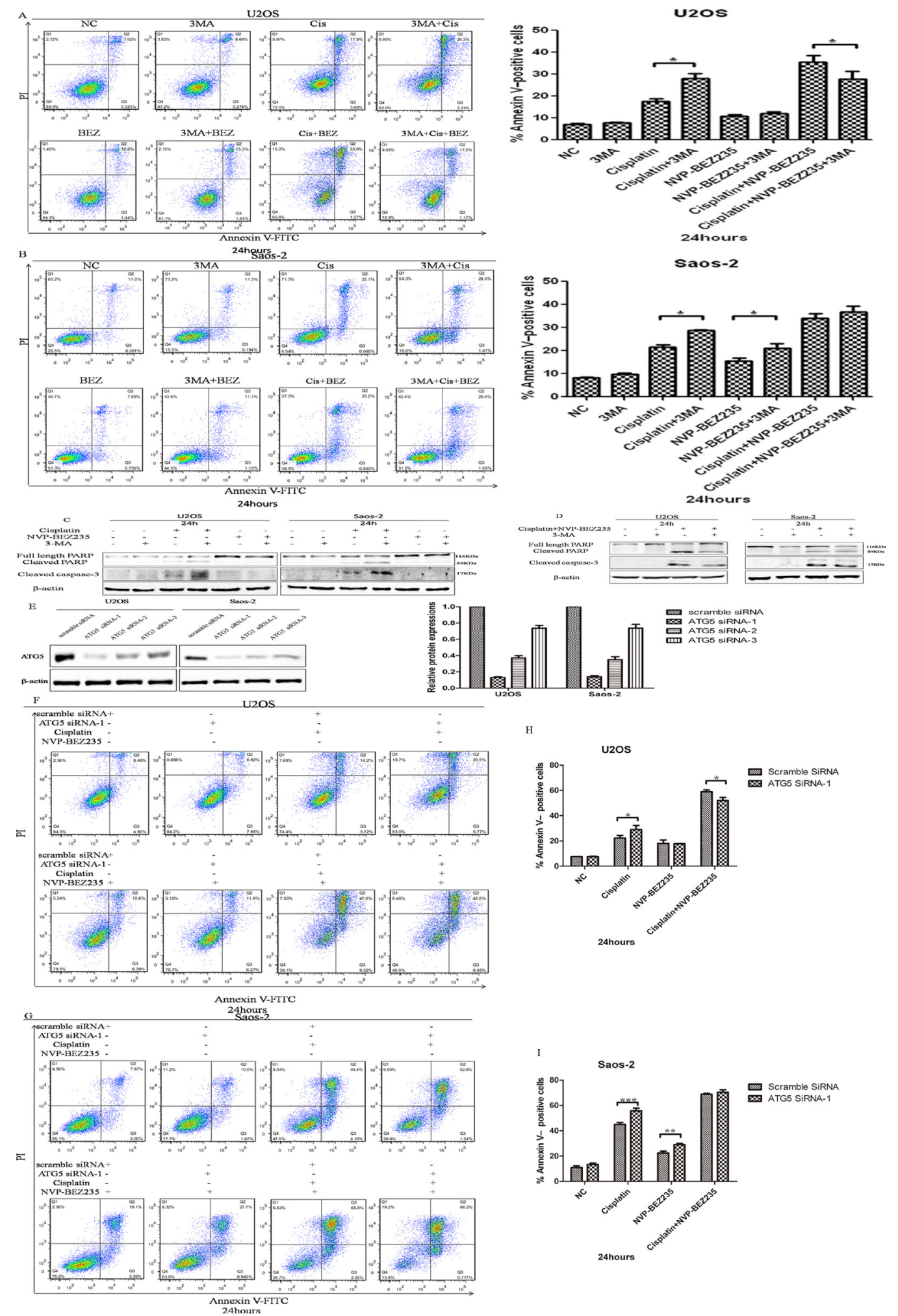

Figure 6: NVP-BEZ235 switches function of autophagy induced by cisplatin in U2OS and Saos-2 cells. (A, B) Representative results of Annexin V-PI dual staining with flow cytometry in U2OS and Saos-2 cells treated with cisplatin or/and NVPBEZ235 with or without 3-MA. (C, D) Cleaved PARP and cleaved caspase-3 expressions were detected in U2OS and Saos-2 cells treated with cisplatin or/and NVP-BEZ235 with or without 3-MA. (E) Generation of ATG5-deficient U2OS and Saos-2 cells with ATG5 siRNAs. $(\mathbf{F}, \mathbf{G})$ Representative results of Annexin V-PI dual staining with flow cytometry in U2OS and Saos-2 cells with or without ATG-5 siRNA-1 silence treated with combined cisplatin and NVP-BEZ235. (H, I) Cleaved PARP expressions were detected in U2OS and Saos-2 cells transfected with control or Atg5 siRNA treated with cisplatin or/and NVP-BEZ235. $\beta$-actin was used as the loading control. Each data represents the mean $\pm \mathrm{SD}$ of triplicate experiments. ${ }^{*} P<0.05,{ }^{* *} P<0.01,{ }^{* * *} P<0.001$. 
and TAp73 and their targeted gene (noxa, puma, p21) expressions. As a result, it seems that the synergistic effects of combined NVP-BEZ235 and cisplatin aren'tdue to enhanced activation of p53 or TAp73 pathway in OS, PI3K-Akt-mTOR pathway regulates p53 or TAp73 pathway in a cell type dependent manner.

Autophagy, an evolutionarily conserved process, mediates lysosomal degradation of cytoplasmic and cellular organelles, has different functions in cells: cytoprotective, cytotoxic, cytostatic and nonprotective [12]. Researches demonstrated that p53 status [18, 49], immunogenic signal $[15,16]$, apoptosis ability [50], HMGB1 redox status [51] can determine the role of autophagy, and autophagy targeting methods can be used to enhance chemosensitivity in cancer cells [52]. As PI3KAkt-mTOR negatively regulates autophagy, function of autophagy induced by cisplatin or/and NVP-BEZ235 in U2OS and Saos-2 cells were tested. Consistent with others' results $[14,39,40]$, autophagy induced by cisplatin promotes chemoresitance, however, combined NVPBEZ235 and cisplatin treatment switched cytoprotective autophagy induced by cisplatin to cytotoxic(in U2OS cells) or nonprotective (in Saos-2 cells). So, it seems that NVP-BEZ235 could sensitize OS to cisplatin through switching autophagy function. However, the underlying mechanism how NVP-BEZ235 switches function of autophagy deserves our further exploration.

Although in vitro data showed that NVP-BEZ235 could be used to enhance cisplatin sensitivity in OS cancer cells, these results must be confirmed and validated in vivo. In our study, we extended in vivo experiments and demonstrated that cisplatin combined with NVP-BEZ235 induced more tumor growth delay compared to cisplatin or NVP-BEZ235 treatment alone. What's more, a pronounced decrease in tumor cell proliferation (Ki67) and increase in apoptosis (TUNEL-positive tumor cells) were noted in combination-treated xenografts based on immunostaining. All these results comfirmed that NVP-BEZ235 could synergize cisplatin sensitivity in OS both in vitro and in vivo.

NVP-BEZ235, an orally available dual PI3K/mTOR inhibitor, has been shown to inhibit PI3K-Akt-mTOR signal activity effectively and have antitumor activity [21-23]. Recently, its efficacy and safetywere assessed in a few Phase I/II clinical trials (www.clinicaltrials.gov). The results of our work showed that NVP-BEZ235 could synergize cisplatin sensitivity in OS and may be a promising adjuvant drug for OS. However, the underlying mechanism why NVP-BEZ235 switches function of autophagy induced by cisplatin deserves our future exploration.
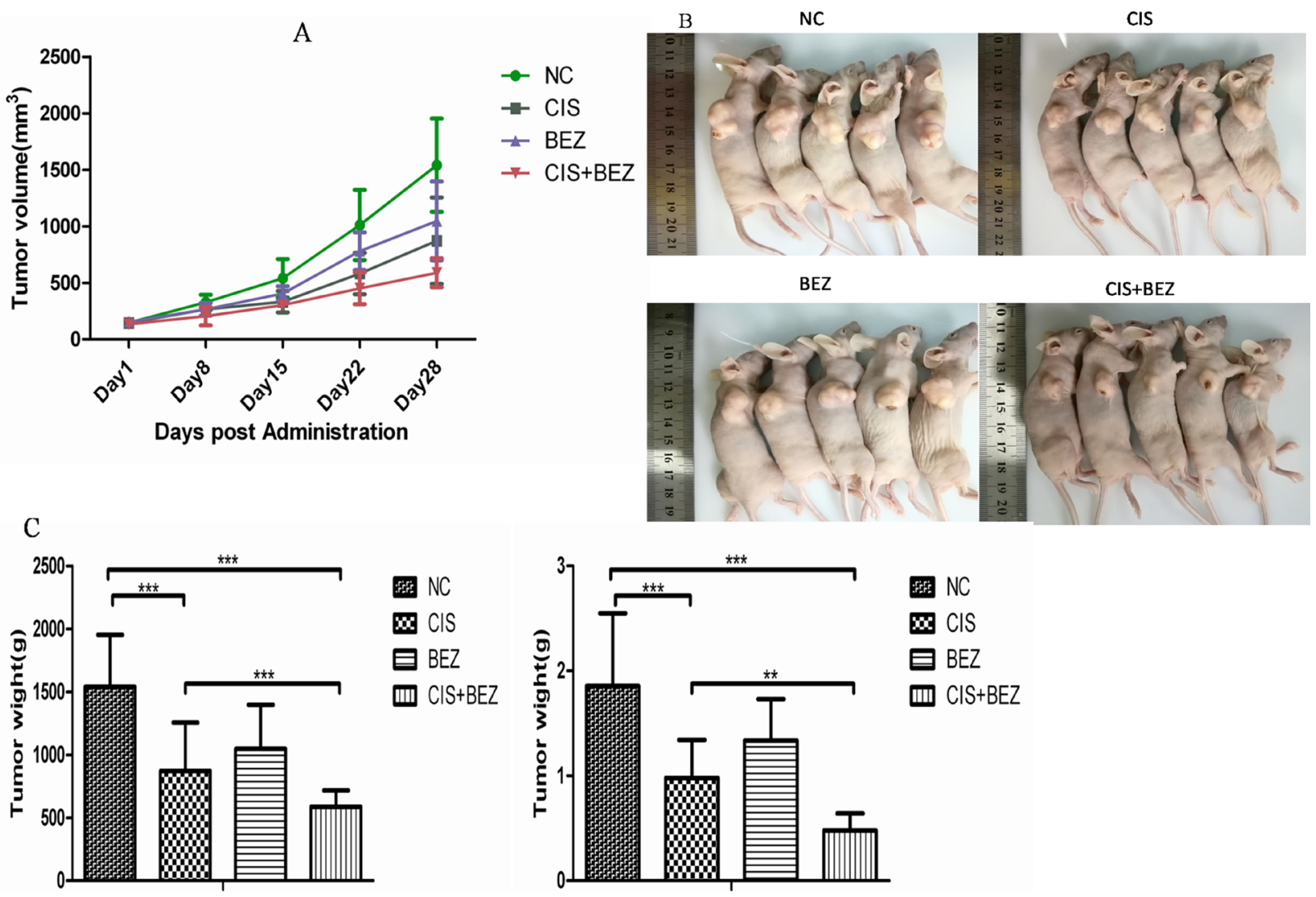

Figure 7: NVP-BEZ235 synergistically enhances growth inhibition effect of cisplatin in vivo. (A) Tumor volume of each group was calculated by a caliper every 7 days. $(\mathbf{B}, \mathbf{C})$ Tumor volume and weight from each group on the 5 th week after tumor implantation are shown. Data are presented as mean tumor volume $\pm \mathrm{SE} .{ }^{*} P<0.05,{ }^{* * *} P<0.001$.CIS is short for cisplatin, BEZ is short for NVP-BEZ235. 


\section{MATERIALS AND METHODS}

\section{Cell lines and culture}

The human osteosarcoma cell lines U2OS, Saos-2 and MG-63 cells were obtained from ATCC. U2OS and Saos-2 cells were cultured in McCoy's 5A medium (Gibco, 16600-082) supplemented with fetal bovine serum (corning, 35-076-CV) a final concentration of $10 \%$ for U2OS and 15\% for Saos-2. MG-63 cells were maintained in Eagle's Minimum Essential Medium(ATCC, 30-2003) supplemented with $10 \%$ fetal bovine serum. The medium was replaced with fresh medium as necessary, and cultures were maintained at $37^{\circ} \mathrm{C}$ in the presence of $5 \% \mathrm{CO}_{2}$.

\section{Chemical compounds and drugs}

NVP-BEZ235 (S1009), cisplatin (S1166), 3-Methyladenine (S2767) and Chloroquine Phosphate (S4157) were obtained from Selleck Chemical in U.S.A. NVP-BEZ235 was provided as a $20 \mathrm{nM}$ stock solution in $100 \%$ DMF. Final DMF concentration was kept constant at $0.1 \%$ in control and compound-treated cells. Cisplatin solution was provided as a $1 \mathrm{mg} / \mathrm{ml}$ stock solution in $0.9 \%$ isotonic saline solution.
3-Methyladenine solution was provided as a $100 \mathrm{mM}$ stock solution in PBS.Chloroquine Phosphatesolution was provided as a $50 \mathrm{mM}$ stock solution in water.Working solutions were prepared freshly before addition to the cell media.NMethylpyrrolidine (NMP,120-94-5) and Polyethylene glycol 300 (PEG300,1546423) were bought from Sigma-Aldrich.

\section{Antibodies}

The following antibodies were used for Western blotting : p73(abcam, USA); p53, Cleaved Caspase-3, PARP (ABclonal, USA); Puma, p21 Waf1/Cip1, S6 Ribosomal Protein, Phospho-S6 Ribosomal Protein, pan-Akt, PhosphoAkt (Ser473), Phospho-Akt(Thr308),NOXA,GAPDH, $\beta$-Actin(Cell Signaling Technologies, USA).

\section{Cell viability by CCK-8 assay}

Cells were treated with cisplatin $(1-100 \mu \mathrm{m})$ or/ and NVP-BEZ235 $(10 \mathrm{nM}-500 \mathrm{nM})$ and the inhibitory effect on cell viabilitywas determined by CCK-8 assay (Dojindo Molecular Technologies, Japan) according to the manufacturer's instructions. In brief, cells were seeded into a 96 -well plate $\left(5 \times 10^{3}\right.$ cells/well $)$ and cultured as
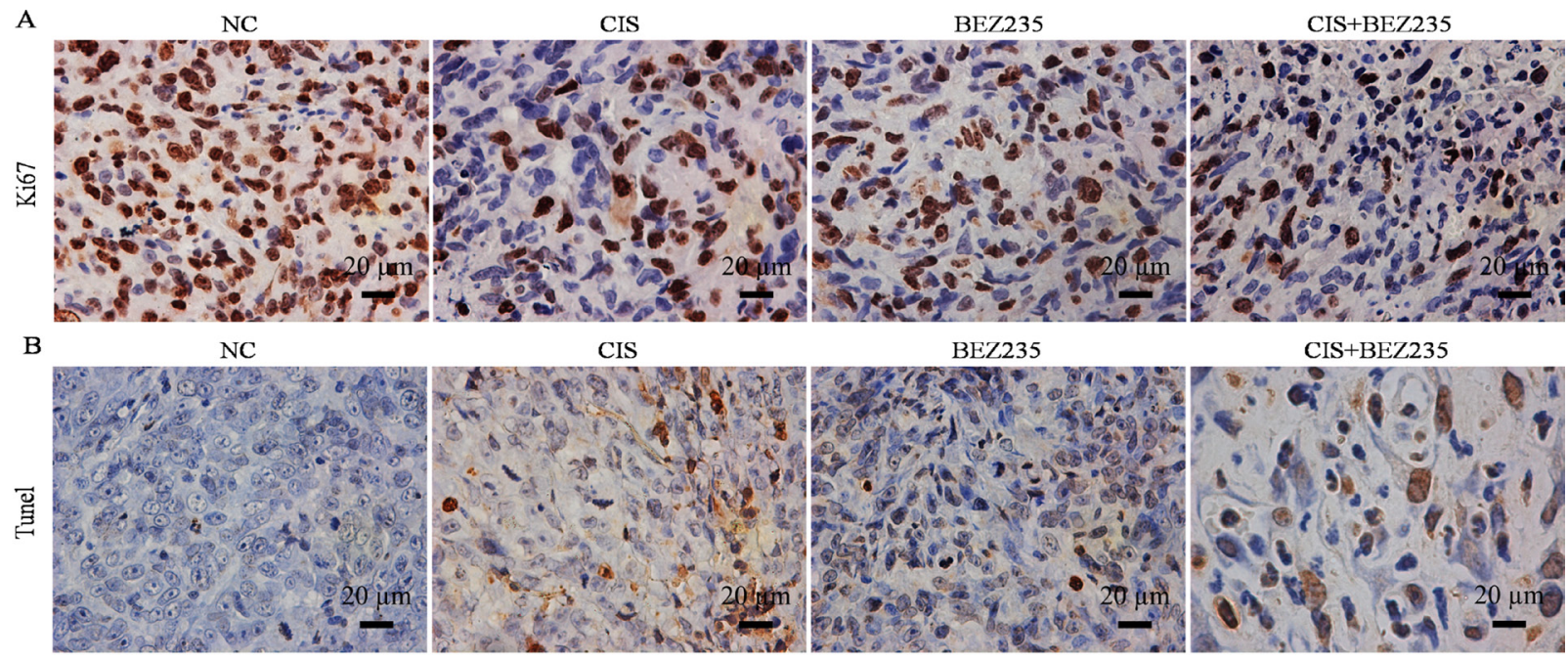

BEZ235

CIS+BEZ235
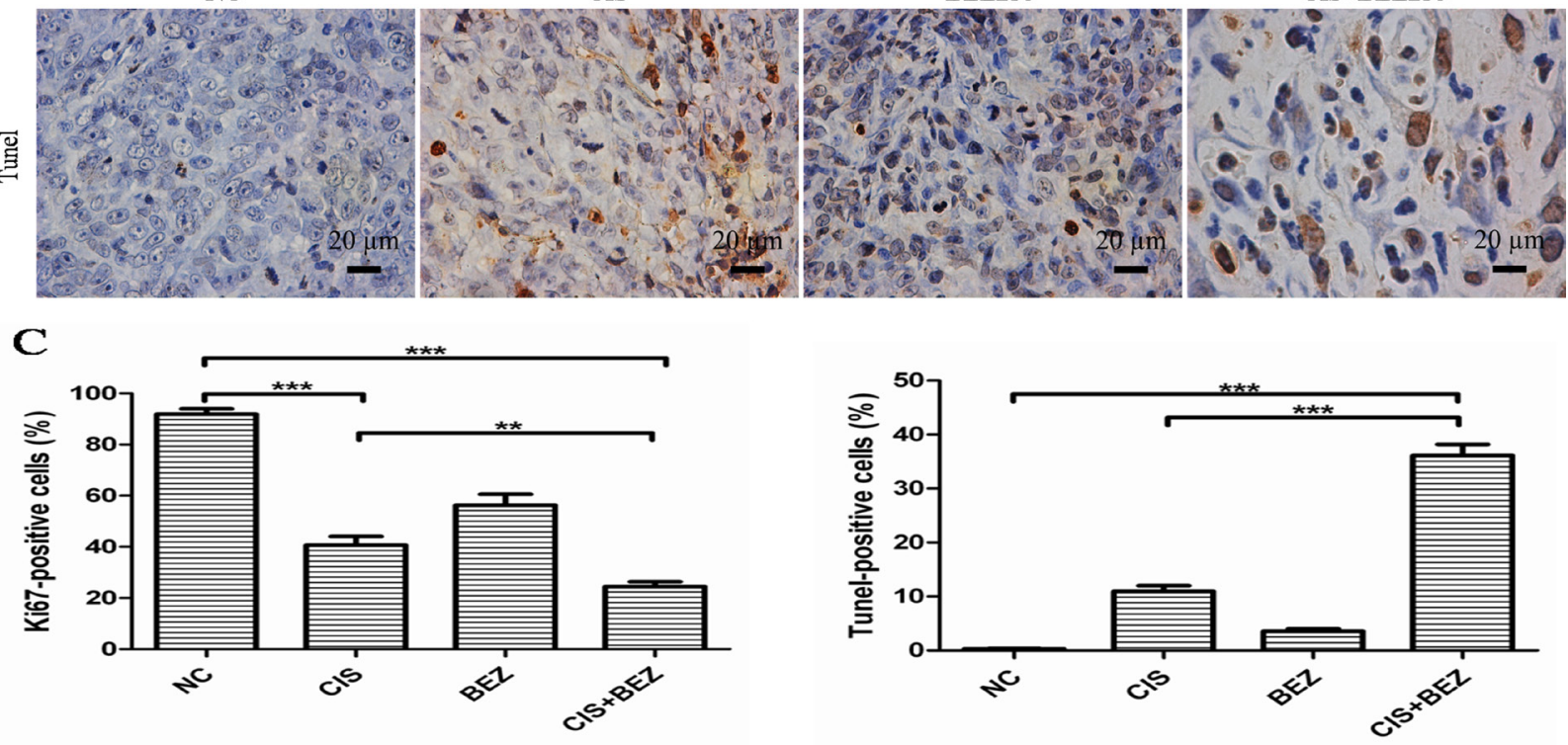

Figure 8: Combined NVP-BEZ235 and cisplatin increases cell apoptosis and decreases cell proliferation compared with cisplatin treatment alone in vivo. (A) Cell proliferation was evaluated by Ki67 staining in tumor tissue (Scale bar $=20$ um, magnification, 400×); (B) Apoptotic cells were labeled by TUNEL assay (Scale bar = 20 um, magnification, 400×); (C) Quantification of Ki67-positive and TUNEL-positive cells in each group (mean \pm S.D., $n=5$ ). ${ }^{* *} P<0.01,{ }^{* * * *} P<0.001$. CIS is short for cisplatin, BEZ is short for NVP-BEZ235. 
described above. After treatment for $48 \mathrm{~h}, 10 \mu \mathrm{L}$ of CCK-8 dye was added to each well, cells were incubated at $37^{\circ} \mathrm{C}$ for $2 \mathrm{~h}$, then, optical density was read at $450 \mathrm{~nm}$ in a multimode microplate reader (Synergy2, BioTek, Winooski, VT). Inhibitory rates were calculated by Microsoft Excel and IC50 values were calculated using the Calcusyn software.

\section{Determination of synergism}

For drug combination experiments, cells were treated with a 20:1 fixed ratio combination of NVPBEZ235 and cisplatinfor $48 \mathrm{~h}$. The data were analyzed by CompuSyn software with the results showed as fraction Combination indexplot and isobologram.According to the median-effect principle, where $\mathrm{CI}<1,=1$, and $>1$ indicate synergism, additive effect, and antagonism, respectively.

\section{Western blot analysis}

Cells were lysed with $2 \%$ SDS, $10 \%$ glycerol, $2 \mathrm{M}$ urea, $10 \mathrm{mM}$ Tris- $\mathrm{HCl}$ (pH 6.8), $10 \mathrm{mM}$ dithiothreitol and $1 \mathrm{mM}$ phenylmethylsulfonyl fluoride. The lysates were centrifuged and the supernatants were separated by SDS-polyacrylamide gel electrophoresis and blotted onto a nitrocellulose membrane (Bio-Rad Laboratories). The membrane was then incubated at $4^{\circ} \mathrm{C}$ overnight with the primary antibody,and subsequently incubated with the HRP conjugated secondary antibody at room temperature for $1 \mathrm{~h}$. Immunoreactive proteins were detected the Western lightning Plus (PerkinElmer) according to the manufacturer's instructions and visualized using the GeneGnome XRQNPC system(SYNGENE).All protein bands were normalized against $\beta$-Actin protein.For result analysis, we first normalized the band intensity of the target protein to $\beta$-actin in each sample, correspondingly. We then normalized the relative target protein levels of the treatment groups to their control group.

\section{Cell cycle analysis}

Cell cycle progressionwas detected using the Cell Cycle Detection Kit (Nanjing Keygen Biotech, China) according to the manufacturer's instructions.Briefly, cells were incubated with cisplatin or /and NVP-BEZ235 for 24 $\mathrm{h}$, trypsinized, washed and harvested, fixed in $70 \%$ ethanol and cell cycle analysis was done using propidium iodide. Samples were analyzed by FACScan flow cytometer (BD Biosciences, CA). The percentage of cells in different phases of the cell cycle was calculated using FlowJo 9.3.0 software (Tree Star Inc., Ashland, OR, USA).

\section{Real-time reverse transcriptase PCR}

Isolated RNA was subjected to reverse transcription and PCR, as described previously [35].The RNA isolater
Total RNA Extraction Reagent(Vazyme, China) was used to isolate total RNA. Reverse transcription was performed using the HiScript II Q RT SuperMix for qPCR (Vazyme, China) to synthesize first-strand cDNA. SYBR green was used to detect dsDNA product during the realtime PCR reaction. The mRNA content was normalized to the housekeeping gene b-actin. The specific primer sequences used for real-time PCR were as follows: for NOXA forward, ATTACCGCTGGCCTACTGTG and reverse, ATGTGCTGAGTTGGCACTGA; PUMA forward, GGCCCAGACTGTGAATCC and reverse, TCACACG TGCTCTCTCTAAACC; P21 forward, TGGTGGCAGTA GAGGCTATG and reverse, AGTCCAGGCCAGTA TGTTAC.ACTIN forward, GCATGGGTCAGAAG GATTCCT and reverse, TCGTCCCAGTTGGTGACGAT.

\section{Detection of apoptosis in vitro and in vivo}

In vitro, apoptosis was detected using the Annexin V-FITC Apoptosis Detection Kit (Nanjing Keygen Biotech, China) according to the manufacturer's instructions. In brief, the cells were harvested and washed twice with cold PBS, then resuspended in $500 \mu \mathrm{L}$ binding buffer. Thereafter, $5 \mu \mathrm{L}$ Annexin V-FITC and $5 \mu \mathrm{L}$ PI were added and the cells were further incubated in the dark for $15 \mathrm{~min}$ at room temperature. Cells were then analyzed on a FACScan flow cytometer (BD Biosciences, CA). In vivo, DNA fragmentation using terminal deoxynucleotidyl transferase-mediated nick end labeling (TUNEL) was conducted to assess apoptosis in tumor tissue following the manufacturer's directions (Merck Corp. Cat. QIA39). The number of TUNEL-positive cells was calculated at $400 \times$ magnification for 5 fields randomly selected in each tumor sample.

\section{mRFP-GFP-LC3 expressing cells generation and fluorescent $\mathrm{LC} 3$ puncta analysis}

To monitor the various stages of autophagy, the tandem GFP-RFP-LC3 adenovirus construct purchased from HanbioInc (Shanghai, China) was used in this study according to the manufacturer's instructions.In brief, to perform image-based analysis for autophagy, simply infected cells with the tandem GFP-RFP-LC3 adenovirus for 36 hours, thencells were treated and imaged for GFP and RFP by using confocal fluorescence microscopy. Green vesicles are considered to be autophagosomes and red vesicles are considered to be both autophagosomes and autolysosomes. The number of autolysosomes was achieved by subtracting the number of green vesicles from that of the red vesicles.

\section{SiRNA knockdown}

We transiently transfected cells with ATG5 siRNA using Lipofectamine RNAi MAX (Invitrogen, USA) in Opti-MEM medium (Invitrogen, USA), according to the 
manufacturer's instructions. The efficiency of transfection was measured by western blot. The siRNA sequences targeting ATG5 were:1) CATCTGAGCTACCCGGATA, 2) CATCTGAGCTACCCGGATA and 3) GCTAGCTGGC TGTCCATAT. The non-silencing sequence was AGGCTA TGAAGAGATAC.

\section{Mice U2OS xenograft}

Female BALB/c mice aged 4 to 6 weeks were purchased from the animal facility of Southern Medical University of China. All mice were maintained in the accredited animal facility of Southern Medical University, and maintained in accordance with the guidelines of NIH. $5 \times 10^{7}$ U2OS cells were injected subcutaneously into the right flank of the mice. When the right flank xenografts were established at about $150 \mathrm{~mm}^{3}$, animals ( 5 mice per group) were administrated with cisplatin $(5 \mathrm{mg} / \mathrm{kg}$ in $0.9 \%$ isotonic saline solution through intraperitoneal injection), NVP-BEZ235 (45 mg/kg in 10\% NMP-90\% PEG300 through oral gavage) or combination. All drugs were freshly prepared and given twice a week for 28 consecutive days. Control mice received vehicle only. All mice were sacrificed 4 weeks after treatment. Tumor volumes $\left(\mathrm{mm}^{3}\right)$ and weight were measured and tumors from each group were excised for histological study. All animals were maintained in accordance with the guidelines of NIH.

\section{Immunohistochemistry (IHC) analysis}

Expression of $\mathrm{Ki} 67$ in xenograft tumor tissues were analyzed by IHC staining. Briefly, tissues were deparaffinized, rehydrated, and subjected to 5-min pressurecooking antigen retrieval, 10-min double endogenous enzyme block, and overnight primary antibody incubation, and subjected to prediluted biotinylated pan-specific universal secondary antibody (Vector laboratories) for 10 min. Signals were detected by adding 3,3'-diaminobenzidine (DAB) substrate hydrogen peroxide and counterstained by hematoxylin QS. All reagents were obtained from Vector Laboratories (Burlingame, CA). Positive expression was defined as $>15 \%$ positive staining in cell population.

\section{Statistical analysis}

Data are expressed as mean \pm standard deviation (S.D.). Every experiment was performed in triplicates and repeated two or three times. Statistical analysis was performed using SPSS 13.0 software. All data involving multiple groups were analyzed with one-way ANOVA followed by Dunnett's test. A value of $P<0.05$ was considered statistically significant.

\section{Author contributions}

$\mathrm{JCH}$ conceived and designed the experiments. JCH, ZFC, SMC,LJY, ZBH and JYOY performed the experiments and analyzed the data. HKL, ZHS, BL, MW and JSL helped in data analysis. JCH wrote the paper. QCL and HL supervised the whole experimental work, and these authors contributed equally. All authors read and approved the final manuscript.

\section{CONFLICTS OF INTEREST}

All the authors declare no conflicts of interest.

\section{FUNDINGS}

This work was supported by grants from the National Natural Science Foundation of China (Grant Nos. 81372869 and 81572628 to Hai Lu).

\section{REFERENCES}

1. Duchman KR, Gao Y, Miller BJ. Prognostic factors for survival in patients with high-grade osteosarcoma using the Surveillance, Epidemiology, and End Results (SEER) Program database. Cancer Epidemiol. 2015; 39:593-99.

2. Ferrari S, Serra M. An update on chemotherapy for osteosarcoma. Expert Opin Pharmacother. 2015; 16:2727-36.

3. Whelan JS, Bielack SS, Marina N, Smeland S, Jovic G, Hook JM, Krailo M, Anninga J, Butterfass-Bahloul T, Böhling T, Calaminus G, Capra M, Deffenbaugh C, et al, and EURAMOS collaborators. EURAMOS-1, an international randomised study for osteosarcoma: results from pre-randomisation treatment. Ann Oncol. 2015; 26:407-14.

4. Janeway KA, Grier HE. Sequelae of osteosarcoma medical therapy: a review of rare acute toxicities and late effects. Lancet Oncol. 2010; 11:670-78.

5. Fruman DA, Rommel C. PI3K and cancer: lessons, challenges and opportunities. Nat Rev Drug Discov. 2014; 13:140-56.

6. Rodon J, Dienstmann R, Serra V, Tabernero J. Development of PI3K inhibitors: lessons learned from early clinical trials. Nat Rev Clin Oncol. 2013; 10:143-53.

7. Moriarity BS, Otto GM, Rahrmann EP, Rathe SK, Wolf NK, Weg MT, Manlove LA, LaRue RS, Temiz NA, Molyneux SD, Choi K, Holly KJ, Sarver AL, et al. A Sleeping Beauty forward genetic screen identifies new genes and pathways driving osteosarcoma development and metastasis. Nat Genet. 2015; 47:615-24.

8. Perry JA, Kiezun A, Tonzi P, Van Allen EM, Carter SL, Baca SC, Cowley GS, Bhatt AS, Rheinbay E, Pedamallu CS, Helman E, Taylor-Weiner A, McKenna A, et al. Complementary genomic approaches highlight the PI3K/ mTOR pathway as a common vulnerability in osteosarcoma. Proc Natl Acad Sci USA. 2014; 111:E5564-73.

9. Subbiah V, Wagner MJ, McGuire MF, Sarwari NM, Devarajan E, Lewis VO, Westin S, Kato S, Brown RE, 
Anderson P. Personalized comprehensive molecular profiling of high risk osteosarcoma: implications and limitations for precision medicine. Oncotarget. 2015; 6:40642-54. https://doi.org/10.18632/oncotarget.5841.

10. Cadwell K. Crosstalk between autophagy and inflammatory signalling pathways: balancing defence and homeostasis. Nat Rev Immunol. 2016; 16:661-75.

11. Zhong Z, Sanchez-Lopez E, Karin M. Autophagy, Inflammation, and Immunity: A Troika Governing Cancer and Its Treatment. Cell. 2016; 166:288-98.

12. Gewirtz DA. The four faces of autophagy: implications for cancer therapy. Cancer Res. 2014; 74:647-51.

13. Huang J, Liu K, Song D, Ding M, Wang J, Jin Q, Ni J. Krüppel-like factor 4 promotes high-mobility group box 1 -induced chemotherapy resistance in osteosarcoma cells. Cancer Sci. 2016; 107:242-49.

14. Huang J, Ni J, Liu K, Yu Y, Xie M, Kang R, Vernon P, Cao L, Tang D. HMGB1 promotes drug resistance in osteosarcoma. Cancer Res. 2012; 72:230-38.

15. Ko A, Kanehisa A, Martins I, Senovilla L, Chargari C, Dugue D, Mariño G, Kepp O, Michaud M, Perfettini JL, Kroemer G, Deutsch E. Autophagy inhibition radiosensitizes in vitro, yet reduces radioresponses in vivo due to deficient immunogenic signalling. Cell Death Differ. 2014; 21:92-99.

16. Michaud M, Martins I, Sukkurwala AQ, Adjemian S, Ma Y, Pellegatti P, Shen S, Kepp O, Scoazec M, Mignot G, RelloVarona S, Tailler M, Menger L, et al. Autophagy-dependent anticancer immune responses induced by chemotherapeutic agents in mice. Science. 2011; 334:1573-77.

17. Guo XL, Hu F, Zhang SS, Zhao QD, Zong C, Ye F, Guo SW, Zhang JW, Li R, Wu MC, Wei LX. Inhibition of p53 increases chemosensitivity to 5-FU in nutrient-deprived hepatocarcinoma cells by suppressing autophagy. Cancer Lett. 2014; 346:278-84.

18. Rosenfeldt MT, O'Prey J, Morton JP, Nixon C, MacKay G, Mrowinska A, Au A, Rai TS, Zheng L, Ridgway R, Adams $\mathrm{PD}$, Anderson KI, Gottlieb E, et al. p53 status determines the role of autophagy in pancreatic tumour development. Nature. 2013; 504:296-300.

19. Zhu YR, Min H, Fang JF, Zhou F, Deng XW, Zhang YQ. Activity of the novel dual phosphatidylinositol 3-kinase/ mammalian target of rapamycin inhibitor NVP-BEZ235 against osteosarcoma. Cancer Biol Ther. 2015; 16:602-09.

20. Gobin B, Battaglia S, Lanel R, Chesneau J, Amiaud J, Rédini F, Ory B, Heymann D. NVP-BEZ235, a dual PI3K/ mTOR inhibitor, inhibits osteosarcoma cell proliferation and tumor development in vivo with an improved survival rate. Cancer Lett. 2014; 344:291-98.

21. Kim KW, Myers CJ, Jung DK, Lu B. NVP-BEZ-235 enhances radiosensitization via blockade of the PI3K/ mTOR pathway in cisplatin-resistant non-small cell lung carcinoma. Genes Cancer. 2014; 5:293-302. https://doi. org/10.18632/genesandcancer.27.
22. Li JR, Cheng CL, Yang CR, Ou YC, Wu MJ, Ko JL. Dual inhibitor of phosphoinositide 3-kinase/mammalian target of rapamycin NVP-BEZ235 effectively inhibits cisplatinresistant urothelial cancer cell growth through autophagic flux. Toxicol Lett. 2013; 220:267-76.

23. Yu Z, Xie G, Zhou G, Cheng Y, Zhang G, Yao G, Chen Y, Li Y, Zhao G. NVP-BEZ235, a novel dual PI3KmTOR inhibitor displays anti-glioma activity and reduces chemoresistance to temozolomide in human glioma cells. Cancer Lett. 2015; 367:58-68.

24. Pellegrino R, Calvisi DF, Neumann O, Kolluru V, Wesely J, Chen X, Wang C, Wuestefeld T, Ladu S, Elgohary N, Bermejo JL, Radlwimmer B, Zörnig M, et al. EEF1A2 inactivates $\mathrm{p} 53$ by way of PI3K/AKT/mTOR-dependent stabilization of MDM4 in hepatocellular carcinoma. Hepatology. 2014; 59:1886-99.

25. Goudarzi KM, Nistér M, Lindström MS. mTOR inhibitors blunt the p53 response to nucleolar stress by regulating RPL11 and MDM2 levels. Cancer Biol Ther. 2014; 15:1499-514.

26. Davaadelger B, Duan L, Perez RE, Gitelis S, Maki CG. Crosstalk between the IGF-1R/AKT/mTORC1 pathway and the tumor suppressors $\mathrm{p} 53$ and $\mathrm{p} 27$ determines cisplatin sensitivity and limits the effectiveness of an IGF-1R pathway inhibitor. Oncotarget. 2016; 7:27511-26. https:// doi.org/10.18632/oncotarget.8484.

27. Khoo KH, Verma CS, Lane DP. Drugging the p53 pathway: understanding the route to clinical efficacy. Nat Rev Drug Discov. 2014; 13:217-36. https://doi.org/10.1038/ nrd4288PMID:24577402.

28. Tomasini R, Tsuchihara K, Wilhelm M, Fujitani M, Rufini A, Cheung CC, Khan F, Itie-Youten A, Wakeham A, Tsao MS, Iovanna JL, Squire J, Jurisica I, et al. TAp73 knockout shows genomic instability with infertility and tumor suppressor functions. Genes Dev. 2008; 22:2677-91.

29. Mayo LD, Donner DB. A phosphatidylinositol 3-kinase/ Akt pathway promotes translocation of Mdm2 from the cytoplasm to the nucleus. Proc Natl Acad Sci USA. 2001; 98:11598-603.

30. Zhang M, Zhang J, Chen X, Cho SJ, Chen X. Glycogen synthase kinase 3 promotes p53 mRNA translation via phosphorylation of RNPC1. Genes Dev. 2013; 27:2246-58.

31. Fujiwara Y, Kawada K, Takano D, Tanimura S, Ozaki K, Kohno M. Inhibition of the PI3 kinase/Akt pathway enhances doxorubicin-induced apoptotic cell death in tumor cells in a p53-dependent manner. Biochem Biophys Res Commun. 2006; 340:560-66.

32. Zheng L, Ren JQ, Li H, Kong ZL, Zhu HG. Downregulation of wild-type p53 protein by HER-2/neu mediated PI3K pathway activation in human breast cancer cells: its effect on cell proliferation and implication for therapy. Cell Res. 2004; 14:497-506. 
33. Rosenbluth JM, Mays DJ, Pino MF, Tang LJ, Pietenpol JA. A gene signature-based approach identifies mTOR as a regulator of p73. Mol Cell Biol. 2008; 28:5951-64.

34. Wong SW, Tiong KH, Kong WY, Yue YC, Chua CH, Lim JY, Lee CY, Quah SI, Fow C, Chung C, So I, Tan BS, Choo $\mathrm{HL}$, et al. Rapamycin synergizes cisplatin sensitivity in basal-like breast cancer cells through up-regulation of p73. Breast Cancer Res Treat. 2011; 128:301-13.

35. Lu H, Yan C, Quan XX, Yang X, Zhang J, Bian Y, Chen Z, Van Waes C. CK2 phosphorylates and inhibits TAp73 tumor suppressor function to promote expression of cancer stem cell genes and phenotype in head and neck cancer. Neoplasia. 2014; 16:789-800.

36. Hu Z, Xu Z, Liao X, Yang X, Dong C, Luk K, Jin A, Lu H. Polo-like kinase 2 acting as a promoter in human tumor cells with an abundance of TAp73. Onco Targets Ther. 2015; 8:3475-88.

37. Hu ZB, Liao XH, Xu ZY, Yang X, Dong C, Jin AM, Lu H. PLK2 phosphorylates and inhibits enriched TAp73 in human osteosarcoma cells. Cancer Med. 2016; 5:74-87.

38. Guo JY, Xia B, White E. Autophagy-mediated tumor promotion. Cell. 2013; 155:1216-19.

39. Kim M, Jung JY, Choi S, Lee H, Morales LD, Koh JT, Kim SH, Choi YD, Choi C, Slaga TJ, Kim WJ, Kim DJ. GFRA1 promotes cisplatin-induced chemoresistance in osteosarcoma by inducing autophagy. Autophagy. 2017; 13:149-68.

40. Zhen YF, Li ST, Zhu YR, Wang XD, Zhou XZ, Zhu LQ. Identification of DNA-PKcs as a primary resistance factor of salinomycin in osteosarcoma cells. Oncotarget. 2016; 7:79417-27. https://doi.org/10.18632/oncotarget.12712.

41. Luetke A, Meyers PA, Lewis I, Juergens H. Osteosarcoma treatment - where do we stand? A state of the art review. Cancer Treat Rev. 2014; 40:523-32.

42. Zhang J, Yu XH, Yan YG, Wang C, Wang WJ. PI3K/ Akt signaling in osteosarcoma. Clin Chim Acta. 2015; 444:182-92.

43. Selvarajah J, Elia A, Carroll VA, Moumen A. DNA damageinduced $\mathrm{S}$ and $\mathrm{G} 2 / \mathrm{M}$ cell cycle arrest requires mTORC2dependent regulation of Chk1. Oncotarget. 2015; 6:427-40. https://doi.org/10.18632/oncotarget.2813.
44. Lai KP, Leong WF, Chau JF, Jia D, Zeng L, Liu H, He L, Hao A, Zhang H, Meek D, Velagapudi C, Habib SL, Li B. $\mathrm{S} 6 \mathrm{~K} 1$ is a multifaceted regulator of Mdm2 that connects nutrient status and DNA damage response. EMBO J. 2010; 29:2994-3006.

45. Yoon MK, Ha JH, Lee MS, Chi SW. Structure and apoptotic function of p73. BMB Rep. 2015; 48:81-90.

46. Bar J, Lukaschuk N, Zalcenstein A, Wilder S, Seger R, Oren M. The PI3K inhibitor LY294002 prevents p53 induction by DNA damage and attenuates chemotherapy-induced apoptosis. Cell Death Differ. 2005; 12:1578-87.

47. Kojima K, Shimanuki M, Shikami M, Samudio IJ, Ruvolo V, Corn P, Hanaoka N, Konopleva M, Andreeff M, Nakakuma H. The dual PI3 kinase/mTOR inhibitor PI-103 prevents $\mathrm{p} 53$ induction by Mdm2 inhibition but enhances p53-mediated mitochondrial apoptosis in p53 wild-type AML. Leukemia. 2008; 22:1728-36.

48. Suvasini R, Somasundaram K. Essential role of PI3-kinase pathway in p53-mediated transcription: implications in cancer chemotherapy. Oncogene. 2010; 29:3605-18.

49. Chakradeo S, Sharma K, Alhaddad A, Bakhshwin D, Le N, Harada H, Nakajima W, Yeudall WA, Torti SV, Torti FM, Gewirtz DA. Yet another function of p53 - the switch that determines whether radiation-induced autophagy will be cytoprotective or nonprotective: implications for autophagy inhibition as a therapeutic strategy. Mol Pharmacol. 2015; 87:803-14.

50. Xiong HY, Guo XL, Bu XX, Zhang SS, Ma NN, Song JR, Hu F, Tao SF, Sun K, Li R, Wu MC, Wei LX. Autophagic cell death induced by 5-FU in Bax or PUMA deficient human colon cancer cell. Cancer Lett. 2010; 288:68-74.

51. Tang D, Loze MT, Zeh HJ 3rd, Kang R. The redox protein HMGB1 regulates cell death and survival in cancer treatment. Autophagy. 2010; 6:1181-83.

52. Kumar A, Singh UK, Chaudhary A. Targeting autophagy to overcome drug resistance in cancer therapy. Future Med Chem. 2015; 7:1535-42. 